\title{
Analisis Komunikasi Interpersonal Yang Efektif Antara Personal Trainer Dengan Member Gym Starfit
}

\author{
Enzo Scifo Jauwinata ${ }^{1}$, Wulan Purnama Sari ${ }^{2}$ \\ ${ }^{1}$ Fakultas Ilmu Komunikasi, Universitas Tarumanagara, Jakarta \\ Email: enzo.915180067@stu.untar.ac.id \\ ${ }^{2}$ Fakultas Ilmu Komunikasi, Universitas Tarumanagara, Jakarta* \\ Email:wulanp@fikom.untar.ac.id
}

Masuk tanggal : 15-12-2021, revisi tanggal : 06-01-2022, diterima untuk diterbitkan tanggal : 16-01-2022

\begin{abstract}
From many places to exercise, one of the place that favored by people was gym. Gym was favored by people because in the gym members can achieve their goals such as losing weight, building muscle, improving posture or just overcoming stress. One of the supporting factors for the members to get their results is good communication between Personal Trainers and gym members and one of the communication type is interpersonal communication. The purpose of this study is to identify and describe the effectivity of interpersonal communication between Personal Trainers and members at Starfit Gym. This research uses an approach with a case study method with a joint approach of Personal Trainers and Starfit gym members. Hubberman and Miles data analysis model used in this study such as data reduction, data presentation, and data conclusions. This study uses validity of triangulation of sources to compare data from sources and triangulation of techniques to test it. From the results of this study, it was found that there was good communication between the Personal Trainer and the members. This can be seen from the dimensions of effective interpersonal communication and from various existing aspects such as opennes, empathy, supportiveness, positiveness, and equality.
\end{abstract}

Keywords: communication, gym, interpersonal communication, member, personal trainer.

\begin{abstract}
Abstrak
Dari banyaknya tempat untuk berolahraga, salah satu tempat yang digemari oleh masyarakat yaitu gym. Gym digemari oleh masyarakat karena di gym member dapat menurunkan berat badan, membentuk otot, memperbaiki postur tubuh atau hanya sekedar menghilangkan stress. Salah satu faktor pendukung agar member dapat memperoleh hasil yang diinginkan yaitu adanya komunikasi yang efektif antara Personal Trainer dengan member gym dan salah satu bentuk komunikasinya yaitu komunikasi interpersonal. Tujuan dari penelitian ini yaitu untuk mengetahui dan menggambarkan keefektifan komunikasi interpersonal antara Personal Trainer dengan member di Starfit Gym. Penelitian ini menggunakan pendekatan kualitatif dengan metode studi kasus dengan pendekatan wawancara bersama Personal Trainer dan member gym Starfit. Teknik analisis data Hubberman dan Miles digunakan pada penelitian ini yaitu reduksi data, penyajian data, dan penarikan kesimpulan. Penelitian ini menggunakan teknik keabsahan berupa triangulasi sumber untuk memudahkan membandingkan data dari narasumber serta triangulasi teknik untuk menguji kredibilitasnya. Dari hasil dari penelitian ini didapatkan hasil bahwa terjalin komunikasi yang baik antara Personal Trainer dengan member. Hal ini terlihat berdasarkan dimensi komunikasi interpersonal yang efektif dan terlihat dari berbagai aspek yang ada seperti keterbukaan (openness), empati (empathy), sikap mendukung (supportiveness), sikap positif (positiveness), dan kesetaraan (equality)
\end{abstract}

Kata Kunci: Gym, Komunikasi, Komunikasi Interpersonal, Member, Personal Trainer. 


\section{Pendahuluan}

Memperhatikan kesehatan sangatlah penting bagi setiap individu. Terdapat beberapa faktor yang berpengaruh bagi kesehatan seseorang seperti perilaku, faktor lingkungan, pelayanan kesehatan, dan keturunan (Wening, 2020). Perilaku merupakan salah satu faktor yang paling berpengaruh karena perilaku dirilah yang memengaruhi kesehatan tubuh. Gaya hidup yang menentukan diri akan menjadi sehat atau tidak. Pemilihan makanan, pola hidup, sampai melakukan olahraga merupakan beberapa faktor perilaku yang memengaruhi kesehatan tubuh.

Gaya hidup sehat sudah mulai banyak dipilih oleh sejumlah masyarakat di Indonesia. Hal ini terlihat dengan banyaknya masyarakat yang semakin banyak melakukan kegiatan olahraga. Salah satu olahraga yang diminati masyarakat yaitu gym. Hal ini dapat dilihat dari banyaknya tempat gym baru yang bermunculan. Gym dapat diartikan sebagxai lokasi atau tempat untuk melakukan kegiatan latihan dan olahraga seperti kardio, senam, maupun atletik (Maketiva, 2021). Gym digemari oleh masyarakat untuk melakukan aktivitas atau kegiatan fisik karena di gym member dapat memperoleh tujuannya seperti menurunkan maupun menaikan berat badan, menaikkan massa otot, memperbaiki postur tubuh atau bahkan hanya sekedar ingin menghilangkan stress dengan berolahraga. Namun pada umumnya orang yang mendaftarkan diri menjadi member di termpat gym bertujuan untuk memiliki postur tubuh yang ideal. Bagi orang yang baru memulai berolahraga di gym biasanya meeka dapat menggunakan bantuan program dari Personal Trainer.

Personal Trainer merupakan seorang tenaga kerja Profesional yang memiliki pengetahuan dan keahlian dalam bidang latihan kebugaran (fitness) yang bertugas untuk membantu klien (member) dalam mencapai tujuannya berdasarkan beberapa faktor dan aspek seperti konsultasi, tanya jawab mengenai program dan pola latihan juga memberikan motivasi dan edukasi dalam menggunakan alat-alat latihan yang terdapat di gym (Muhammad, 2017).

Salah satu faktor pendukung agar member dapat memperoleh hasil yang diinginkan yaitu adanya komunikasi yang baik antara member dengan Personal Trainer di gym. Komunikasi interpersonal yang dilakukan oleh Personal Trainer dengan member menggunakan pendekatan usaha yang berbeda karena setiap orang memiliki karakter, sifat, kepentingan, dan goals yang berbeda satu sama lain, hal itu juga sama seperti member yang memiliki goals berbeda-beda.

DeVito menjelaskan bahwa Komunikasi interpersonal merupakan proses pengiriman dan penerimaan pesan oleh dua individu atau lebih dengan beberapa efek atau umpan balik seketika. Menurut Rakhmat dalam Prakoso (2017) Komunikasi interpersonal merupakan komunikasi yang paling sering dilakukan masyarakat dalam keseharian. Dalam prosesnya, komunikasi interpersonal yang dilakukan setiap orang mengandung elemen-elemen proses komunikasi, contohnya, setiap orang akan membahas mengenai latar belakang dan pengalaman mereka dalam perbincangan tersebut.

Studi mengenai penggunaan komunikasi interpersonal antara personal trainer dengan membernya menjadi studi yang menarik untuk diteliti. Penelitian ini terfokus pada bentuk-bentuk komunikasi interpersonal yang terjadi atau diperlihatkan oleh Personal Trainer dengan member di gym Starfit. Oleh karena itu peneliti melakukan penelitian mengenai Analisis Komunikasi Interpersonal Yang Efektif Antara Personal Trainer Dengan Member Starfit. Tujuan dari penelitian ini yaitu agar peneliti dapat 
mengetahui keefektifan komunikasi interpersonal yang dilakukan oleh Personal Trainer dengan member Starfit Gym.

Peneliti tertarik untuk melakukan penelitian di gym Starfit karena menurut peneliti gym Starfit merupakan salah satu gym sedang berkembang dan memiliki beberapa cabang di Jakarta. Sudah terdapat 2 cabang di Jakarta yaitu di mall Grand Paragon dan mall Balai Kota Tangerang. Kegiatan di dalam gym tidak hanya sebatas untuk melakukan melatih fisik tetapi juga menjadi tempat untuk menjalin relasi antara personal trainer dengan member. Untuk menjalin bunungan yang baik, Personal Trainer bertugas untuk menjaga relasi yang baik dengan member.

Penelitian ini juga menggunakan referensi penelitian terdahulu dari Gunawan \& Sari (2021) yang berjudul Marketing Communications During the 2020 Pandemic (Case Study of The Star Fit Grand Paragon). Penelitian tersebut menggunakan metode penelitian yang sama seperti penulis yaitu kualitatif sedangkan perbedaannya yaitu penelitian ini membahas mengenai marketing communication sedangkan peneliti membahas mengenai komunikasi interpersonal.

\section{Metode Penelitian}

Penelitian ini menggunakan pendekatan kualitatif dengan metode studi kasus dengan pendekatan wawancara bersama Personal Trainer dan member gym Starfit. Subjek dalam penelitian ini yaitu 2 Personal Trainer dan 2 member Starfit Gym dan objek penelitiannya adalah keefektifan komunikasi interpersonal antara Personal Trainer dengan member Starfit Gym. Teknik analisis data yang peneliti gunakan yaitu model Hubberman dan Miles yang terdiri dari reduksi data, penyajian data, dan penarikan kesimpulan. Kemudian penelitian ini menggunakan Teknik keabsahan data berupa triangulasi sumber untuk memudahkan membandingkan data dari narasumber serta triangulasi teknik untuk menguji kredibilitasnya.

\section{Hasil Temuan dan Diskusi}

Dari hasil yang wawancara yang peneliti lakukan, peneliti memperoleh bahwa bentuk penyampaian pesan yang terjadi antara Personal Trainer dengan member Starfit Gym tersampaikan dengan baik. Hal ini dijelaskan berdasarkan dimensi komunikasi interpersonal yang efektif oleh Devito dalam Irawan (2017) dan terlihat dari berbagai aspek yang ada seperti keterbukaan, empati, sikap mendukung, sikap positif, dan kesetaraan.

Pertama, keterbukaan merupakan sikap dapat menerima saran dari orang lain dan mau memberikan informasi kepada orang lain. Artinya yaitu mau membuka diri kepada orang lain ketika orang lain membutuhkan informasi yang dibutuhkannya (Devito dalam Irawan, 2017). Sikap keterbukaan dapat diketahui melalui wawancara yang peneliti lakukan dengan bertanya "Apakah Personal Trainer mau menerima masukan dari member dan sebaliknya?" kepada Personal Trainer Gym Starfit.

"Itu merupakan hal wajib seperti Personal Trainer memberikan masukan dan arahan, mungkin ada member yang tidak mau mendengarkan masukan dan arahan tapi setidaknya Personal Trainer sudah memberikan masukan dan arahan. Selain itu Personal Trainer juga menerima masukan dari member untuk memperbaiki diri. Mungkin Personal Trainer memiliki sikap yang salah atau kurang baik bagi para member maka Personal Trainer 
akan menerima masukan untuk memperbaiki diri. Personal Trainer dengan member bersikap saling terbuka" (Donny).

"Seorang Personal Trainer juga manusia jadi Personal Trainer juga butuh dikoreksi oleh member juga agar kedepannya bisa menjadi lebih baik lagi. Begitu juga member menerima masukan juga jadi saling mengoreksi diri" (Sigit).

Pada penelitian ini peneliti menemukan adanya sikap keterbukaan antara Personal Trainer dengan member. Menurut Donny sebagai Personal Trainer di Starfit Gym, Personal Trainer yang baik adalah dengan mendekatkan diri dengan cara lebih terbuka terhadap member. Keterbukaan tersebut dapat terlihat dari bagaimana Personal Trainer memberikan saran dan arahan kepada member serta menerima saran dari member. Hal ini sejalan dengan salah satu sikap positif keterbukaan yaitu sikap dapat menerima saran dan mau memberikan informasi kepada orang lain yang berarti seseorang mau membuka diri kepada orang lain ketika orang lain membutuhkan informasi yang dibutuhkannya (Devito dalam Irawan, 2017).

Komunikasi interpersonal akan berjalan dengan baik ketika ada timbal balik bergantian dalam saling menerima informasi. Suasana dialogis ini mencipatakan keterbukaan antara komunikator dan komunikan (Afriyadi, 2015). Dengan keterbukaan serta umpan balik yang baik maka dapat membangun rasa kepercayaan diantara keduanya yang kemudian dapat menciptakan hubungan yang harmonis. Dalam hal ini tidak hanya Personal Trainer yang memberikan saran kepada member tetapi member juga berhak memberikan saran kepada Personal Trainer terkait dengan pelayanan yang diberikan kepada member.

Kedua yaitu empati. Empati merupakan kemampuan seseorang untuk merasakan dan memahami hal yang dirasakan orang lain, serta dapat memahami suatu persoalan bukan dari dari sudut pandangnya sendiri melainkan juga dari sudut pandang orang lain (Devito dalam Irawan, 2017). Peneliti mengetahui terdapat sikap empati yang terjalin antara Personal Trainer dengan member pada melalui pertanyaan "Apakah pernah membahas topik yang sifatnya pribadi (diluar dari topik tentang gym)? Jika pernah tentang apa, siapa yang memulai, lalu bagaimana reaksi/ tanggapan dari Personal Trainer dan sebaliknya?"

"Sering karena Personal Trainer dengan member sudah seperti teman namun Personal Trainer lebih menghotmati member dan yang seperti kita tahu pasti dalam pertemanan ada seperti curhatan pribadi, masalah keluarga, masalah internal, masalah keuangan, dan sebagainya. Bisa member yang memulai duluan atau Personal Trainer yang memulai duluan namun Personal Trainer agak sedikit canggung untuk memulai duluan karena ini mencakup ruang lingkup kerja bukan pribadi namun kalau member yang memulai duluan maka Personal Trainer akan welcome terhadap member, bahkan ada beberapa member yang datang ke gym bukan untuk latihan melainkan untuk curhat dengan Personal Trainernya. Misalkan dia mengambil satu jam sesi maka member menggunakan jam tersebut untuk ngobrol dengan Personal Trainer karena member sudah merasa nyaman dengan Personal Trainer tersebut" (Donny).

"Ada juga hal-hal yang dibahas yang menyangkut urusan pribadi seperti yang sudah disebutkan sebelumnya seperti member yang curhat ke Personal Trainer dan Personal Trainer menanggapi 
curhatan tersebut seprofesional mungkin. Kalau bisa diberi masukan maka Personal Trainer akan memberikan masukan kepada member begitu juga sebaliknya. Untuk siapa yang memulai duluan biasanya member yang memulai duluan" (Sigit).

"Karena sudah dekat dengan Personal Trainer maka biasanya sudah membahas tentang hal pribadi seperti bercerita tentang kehidupan, tentang pekerjaan, keseharian, seperti curhat dan untuk respon dari Personal Trainer juga bagus dan saling mendukung" (Kezia).

"Pernah membahas tentang kehidupan pribadi contohnya bercerita kemarin abis darimana makannya enak dan reaksinya selalu positif dan untuk siapa yang memulai duluan biasanya bergantian" (Olivia).

Peneliti melihat terdapat sikap empati yang terjadi antara Personal Trainer dengan member karena sesuai dengan pernyataan bahwa "Personal Trainer dengan member sudah seperti teman". Tidak hanya membahas mengenai seputar pola hidup sehat tetapi Member dapat bercerita mengenai masalah pribadi, keluarga, internal, keuangan, dan topik lainnya dan Personal Trainer menanggapi topik tersebut dan memberikan masukan kepada member. Hal ini menunjukkan bahwa empati yang terjalin antara Personal Trainer dengan member terjalin dengan baik. Ini sejalan dengan penelitian Adha (2017) dimana dalam penelitian tersebut dinyatakan bahwa tidak hanya pelatihan saja yang diberikan, tetapi member juga membutuhkan sikap empati terhadap apa yang terasa sebagai salah satu bentuk motivasi.

Ketiga, sikap saling mendukung. Hubungan interpersonal yang efektif akan terjadi apabila ada sikap saling mendukung dalam hubungan tersebut (Devito dalam Irawan, 2017). Sikap saling mendukung antara Personal Trainer dengan member dapat diketahui oleh peneliti pada saat peneliti menanyakan "Apakah terdapat sikap saling mendukung antara Personal Trainer dan member gym? dan bagaimana sikap saling mendukung yang terjadi antara Personal Trainer dengan member gym?"

"Harus support, member itukan butuh support, bukan hanya koreksi, edukasi juga untuk menunjang goals dari member itu sendiri. Bentuknya itu seperti Personal Trainer yang selalu mengedukasi member, memberikan support, mengingatkan member mengenai pola istirahat, makan, tidur, dan latihan" (Sigit).

"Sikap saling mendukung itu pasti karena Personal Trainer harus dapat memotivasi member agar member dapat rutin latihan karena tugas Personal Trainer tidak hanya mengajar melainkan juga memberikan motivasi, edukasi dan memberikan arahan yang baik. Sikap saling mendukungnya seperti memberikan motivasi kemudian selalu memberikan salam kepada member seperti mengucapkan selamat pagi, kemudian juga mengingatkan member kalau ada latihan hari ini dan sebagainya" (Donny).

"Selama ini terdapat sikap saling mendukung, saling memberi tahu kelebihan dan kekurangan satu sama lain, apalagi member sudah membayar untuk Personal Trainer maka Personal Trainer pasti mendukung member. Bentuk sikap saling mendukung seperti Personal Trainer mengingatkan member untuk latihan, mengingatkan pola makan, tidur, latihan dan menanyakan progress 
dari member" (Kezia). "Pasti karena saat kita sedang workout Personal Trainer pasti mendukung kita agar badan kita cepat bagus dan mencapai body goals. Kita sebagai member mendukung Personal Trainer yaitu dengan menjadi client setia dan tetap menggunakannya terus" (Olivia).

Sikap saling mendukung sangatlah penting agar komunikasi yang berlangsung dapat berlangsung dengan baik sehingga tujuan komunikasi tersebut dapat tercapai. Personal Trainer dengan member saling memberi support satu sama lain. Sikap saling mendukung dapat dilihat dari bagaimana Personal Trainer memberi edukasi kepada member, memberikan support, mengingatkan member mengenai pola istirahat, makan, dan latihan (mengingatkan sehari sebelum latihan). Sedangkan sikap saling mendukung dari member dengan melakukan arahan yang diberikan oleh Personal Trainer serta memberi tahu kelebihan dan kekurangan satu sama lain. Sikap tersebut sama seperti yang dikemukakan oleh Devito dalam Irawan (2017) bahwa hubungan interpersonal yang efektif akan terjadi jika ada sikap saling mendukung dalam hubungan tersebut. Hal ini menunjukkan bahwa Personal Trainer dan member yang memiliki komitmen untuk melakukan interaksi secara terbuka.

Keempat adalah sikap positif. Sikap positif diperlihatkan dari pihak yang melakukan komunikasi interpersonal harus mempunyai perasaan dan pikiran yang positif (Devito dalam Irawan, 2017). Sikap ini dapat diketahui pada saat peneliti bertanya "Bagaimana cara Personal Trainer untuk dapat memahami keinginan member gym?

"Jadi Personal Trainer harus tau dulu member datang untuk ngapain, mau dapat apa. Misalkan member request ingin otot dadanya lebih besar maka Personal Trainer harus fokus melatih otot dada member mungkin dalam seminggu kita lebih banyak melatih otot dada dibanding otot lainnya." (Donny).

"Pasti ada namanya Fitness Goals atau tujuan dari fitness itu apa. Jadi member datang dari awal itu ditanya keinginannya apa, yang pasti Personal Trainer menyesuaikan dengan keinginan member misalkan member ingin mengencangkan bagian lengan maka Personal Trainer akan melatih bagian lengan agar tujuan member dapat tercapai. Dan di awal sebelum member mengambil sesi latihan dengan Personal Trainer terdapat sesi tanya jawab agar Personal Trainer dapat lebih mengetahui keinginan dari member itu seperti apa." (Sigit).

Selain itu, sikap positif juga terlihat melalui pertanyaan "Bagaimana kondisi komunikasi bila member sudah tidak menjadi member di gym atau pindah Personal Trainer?”

"Komunikasi tetap berlangsung dengan baik namun sudah tidak sedekat dulu pada saat menjadi client. Jadi sudah tidak ada ucapan lagi selamat pagi dan reminder dari Personal Trainer terhadap member. Jika dulunya member menjadi client dari Personal Trainer A kemudian dia pindah ke Personal Trainer B maka Personal Trainer A akan tetap berkomunikasi dengan baik dengan member dan Personal Trainer A menanyakan apakah terdapat kesalahan pada saat dulu melatih member dan sebagainya" (Donny). 
"Personal Trainer selalu menanyakan kabar, Personal Trainer tetap mengingatkan member mau pindah dengan Personal Trainer siapapun itu bebas jangan merasa tidak enak karena belajar sama siapapun tidak masalah. Karena antar Personal Trainer mungkin beda cara latihannya tapi goals yang ingin dituju tetap sama" (Sigit).

"Baik-baik aja sih, Personal Trainer tetap professional dan kita tetap temenan bagaimanapun kan kita pernah dekat dan pernah akrab, jadi hubungannya baik-baik aja" (Olivia).

Sikap positif ditunjukkan melalui sikap saling menghargai antara Personal Trainer dengan member. Hal ini ditunjukkan dalam cara Personal Trainer memperlakukan member jika member sudah tidak menjadi client lagi. Personal Trainer tetap berkomunikasi dengan baik namun sudah tidak sedekat dulu pada saat menjadi client. Contohnya sudah tidak ada ucapan lagi selamat pagi dan reminder dari Personal Trainer terhadap member karena member sudah tidak menjadi client lagi. Walaupun begitu, Personal Trainer tetap memperlakukan member dengan baik seperti sebelumnya agar komunikasi yang terjalin tetap bertahan dengan baik. Hal ini sejalan dengan pernyataan bahwa sikap positif terlihat dari perilaku dan sikap, seperti: saling menghargai, berpikir positif, tidak curiga, merasa orang lain penting, memberikan pujian dan penghargaan, dan memiliki komitmen dalam bekerjasama (Devito dalam Irawan, 2017).

Kelima yaitu kesetaraan. Kesetaraan merupakan adanya perasaan bahwa kedua orang sama-sama penting, berharga dan bernilai, dan membutuhkan (Devito dalam Irawan, 2017). Peneliti mendapatkan kesetaraan yang terjadi melalui pertanyaan "Apakah terdapat kesetaraan dalam komunikasi antara Personal Trainer dengan member? Apakah terdapat perasaan bahwa Personal Trainer lebih tinggi dari member maupun sebaliknya?"

"Ya, dalam komunikasi antara Personal Trainer dengan member setara dan tidak ada perasaan seperti Personal Trainer lebih tinggi dari member maupun sebaliknya dan Personal Trainer lebih baik merendah karena tidak ada orang yang suka direndahkan. Setidaknya kita menghormati orang lain agar orang lain hormat balik kepada kita. Personal Trainer dengan member saling sharing dan saling berbagi ilmu" (Donny).

"Selama ini tidak ada perasaan siapa yang lebih tinggi. Contohnya saya memiliki client seorang dokter dan saya bilang bahwa saya hanya bisa memprogram latihannya aja tapi saya gak berani untuk mengedukasi pola makan dan pola istirahat karena client saya dokter sehingga saya takut terlihat lebih bodoh tetapi dia selalu bilang tidak, kita sama-sama belajar. Dalam latihan ini kita tidak ada yang namanya saling menggurui. Selain itu juga ilmu dama dunia fitness selalu berkembang sehingga kita selalu saling belajar" (Sigit).

"Tidak ada sih, Personal Trainer dengan member setara tidak ada yang merasa lebih tinggi ataupun lebih rendah" (Kezia).

"Ya, terdapat kesetaraan antara Personal Trainer dengan member dan tidak ada perasaan bahwa Personal Trainer lebih tinggi dari member dan sebaliknya karena Personal Trainer dengan 
memberkan saling membutuhkan, Personal Trainer butuh member sebagai client dan member butuh Personal Trainer agar goals badan member dapat tercapai” (Olivia).

Kesetaraan yaitu bahwa diri kita setara dengan orang lain, sadar akan kepentingan yang berbeda, mengakui kepentingan orang lain, tidak memaksakan kehendak sendiri, komunikasi yang terjadi dua arah, susana komunikasi akrab dan nyaman (Devito dalam Irawan, 2017). Dalam komunikasi antara Personal Trainer dengan member setara dan tidak ada perasaan bahwa Personal Trainer lebih tinggi dari member maupun sebaliknya.

Personal Trainer dengan member saling sharing dan berbagi ilmu. Contoh ini dapat kita lihat dari Sigit Personal Trainer Starfit yang memiliki client seorang dokter dan pada saat ia berkata bahwa ia hanya bisa memberi program latihannya saja tetapi tidak berani untuk mengedukasi pola makan dan pola istirahat karena clientnya yang seorang dokter pasti lebih mengerti mengenai pola makan dan istirahat tetapi clientnya selalu berkata bahwa kita sama-sama saling belajar dan berbagi ilmu.

Pernyataan Olivia yang mengatakan Personal Trainer dengan member saling membutuhkan, Personal Trainer butuh member sebagai client dan member butuh Personal Trainer agar goals badan member dapat tercapai sesuai dengan yang dinyatakan oleh Adha (2017) bahwa kesetaraan (Equality) yang ditunjukkan antara Personal Trainer dan member dalam menjalankan pola hidup sehat memberikan keuntungan dan kebergantungan. Hal ini menunjukkan bahwa terdapat kesetaraan antara Personal Trainer dengan member begitu pula sebaliknya.

\section{Simpulan}

Berdasarkan data yang telah peneliti dapatkan, dapat peneliti simpulkan bahwa terjalin komunikasi yang baik dan efektif antara Personal Trainer dengan member. Hal ini terlihat berdasarkan dimensi komunikasi interpersonal yang efektif oleh Devito dalam Irawan (2017) dan terlihat dari berbagai aspek yang ada seperti keterbukaan, empati, sikap mendukung, sikap positif, dan kesetaraan.

Dari sisi keterbukaan terlihat bahwa Personal Trainer dengan member saling terbuka dengan cara saling memberikan masukan dan arahan satu sama lain. Personal Trainer memberikan arahan kepada member mengenai cara menggunakan alat gym, pola makan, dan pola istirahat namun Personal Trainer juga menerima masukan dari member begitu juga member sebaliknya mau menerima arahan dari Personal Trainer dan memberikan masukan.

Dari sisi empati terlihat bahwa Personal Trainer dengan member saling berempati satu sama lain dan sudah seperti teman. Pada saat di gym, Personal Trainer dan member tidak hanya membahas seputar pola hidup sehat melainkan juga membahas hal-hal yang bersifat pribadi. Hal ini menunjukkan bahwa Personal Trainer berempati terhadap member dengan mau mendengarkan cerita atau curhatan dari member.

Dari sisi sikap saling mendukung, Personal Trainer dan member saling mendukung satu sama lain. Sikap saling mendukung yang dilakukan oleh Personal Trainer yaitu memberikan edukasi kepada member, selalu mengingatkan member untuk latihan, dan juga memberi tahu member pola latihan, pola makan, dan pola istirahat yang baik. Sedangkan sikap saling mendukung yang ditunjukkan oleh 
member yaitu dengan mengikuti arahan dari Personal Trainer dan memberi tahu kelebihan dan kekurangan satu sama lain.

Sikap positif juga ditunjukkan oleh Personal Trainer dan member dengan sikap saling menghargai. Jika seorang member sudah tidak menjadi client dari Personal Trainer makan Personal Trainer tetap berkomunikasi dengan baik. Personal Trainer tetap memperlakukan member dengan baik seperti sebelumnya agar komunikasi yang terjalin tetap bertahan dengan baik.

Kesetaraan ditunjukkan antara Personal Trainer dengan member dengan tidak adanya sikap siapa yang lebih tinggi dan baik Personal Trainer maupun member itu setara. Personal Trainer dan member menyadari bahwa keberadaannya sama-sama penting sehingga Personal Trainer dan member dapat berkomunikasi dengan nyaman dan saling sharing sehingga goals member dapat tercapai.

\section{Ucapan Terima Kasih}

Penulis ingin menyampaikan rasa terima kasih yang sebesar - besarnya kepada pihak yang telah membantu dan mendukung penulis selama proses penulisan skripsi ini, yaitu kepada narasumber yaitu Donny dan Sigit selaku Personal Trainer Starfit Gym serta Kezia dan Olivia selaku member Starfit Gym mendukung dan menyemangati penulis selama proses pembuatan skripsi ini.

\section{Daftar Pustaka}

Adha, A. M., \& Rimayanti, N. (2017). Interpersonal Communication Between Instructor and Member in Running Healthy Lifestyles at Fitness Hotel Grand Elite Pekanbaru (Doctoral dissertation, Riau University).

Afriyadi, F. (2015). Efektivitas komunikasi interpersonal antara atasan dan bawahan karyawan PT. Borneo enterprsindo samarinda. Jurnal Ilmu Komunikasi, 3(1), 362-376.

Gunawan, G. H., \& Sari, W. P. (2021). Marketing Communications During the 2020 Pandemic. In International Conference on Economics, Business, Social, and Humanities (ICEBSH 2021), 685-690. Atlantis Press.

Irawan, S. (2017). Pengaruh konsep diri terhadap komunikasi interpersonal mahasiswa. Scholaria: Jurnal Pendidikan Dan Kebudayaan, 7(1), 39-48.

Maketiva. (2021). Perbedaan Gym dan Fitness Yang Perlu Anda Ketahui. Diakses pada tanggal 20 Agustus 2021. https://www.ruparupa.com/blog/perbedaangym-dan-fitnes-yang-perlu-anda-ketahui/

Muhamad, F. W. (2017). Komunikasi Interpersonal Antara Personal Trainer Dengan Member Di Urban Gym Bandung (Doctoral Dissertation, Perpustakaan).

Prakoso, F. M. (2017). Hubungan Antara Intensitas Penggunaan Gadget dan Komunikasi Interpersonal pada Mahasiswa (Doctoral dissertation, Universitas Islam Indonesia).

Raharjo, J. (2015). Pola Komunikasi Pelatih dengan Atlet Basket (Studi Kasus Komunikasi Interpersonal Pelatih dengan Atlet Basket dalam Memicu Prestasi di Sritex Dragons Solo). Skripsi, FISIP Jurusan Ilmu Komunikasi UNS.

Wening, Tyas. (2020). Kesehatan Penting Untuk Tubuh Kita, Ketahui 4 Faktor Yang Memengaruhi Kesehatan Tubuh. Diakses pada tanggal 20 Agustus 2021. https://bobo.grid.id/read/082439448/kesehatan-penting-untuk-tubuh-kitaketahui-4-faktor-yang-memengaruhi-kesehatan-tubuh?page=all 